University of Nebraska - Lincoln

DigitalCommons@University of Nebraska - Lincoln

2008

\title{
A Two-Part Measure of Degree of Invasion for Cross-Community Comparisons
}

Qinfeng Guo

U.S. Geological Survey

Amy Symstad

U.S. Geological Survey, asymstad@usgs.gov

Follow this and additional works at: https://digitalcommons.unl.edu/usgsnpwrc

Part of the Other International and Area Studies Commons

Guo, Qinfeng and Symstad, Amy, "A Two-Part Measure of Degree of Invasion for Cross-Community Comparisons" (2008). USGS Northern Prairie Wildlife Research Center. 18.

https://digitalcommons.unl.edu/usgsnpwrc/18

This Article is brought to you for free and open access by the US Geological Survey at DigitalCommons@University of Nebraska - Lincoln. It has been accepted for inclusion in USGS Northern Prairie Wildlife Research Center by an authorized administrator of DigitalCommons@University of Nebraska - Lincoln. 


\title{
A Two-Part Measure of Degree of Invasion for Cross-Community Comparisons
}

\author{
QINFENG GUO* $\ddagger$ AND AMY SYMSTAD $\dagger$
}

*U.S. Geological Survey, Northern Prairie WRC, Jamestown, ND 58401, U.S.A., and U.S. Department of Agriculture-Southern Research Station, 200 W.T. Weaver Boulevard, Asheville, NC 28804, U.S.A., email qguo@fs.fed.us †U.S. Geological Survey, Northern Prairie WRC, Black Hills Station, Wind Cave National Park, 26611 U.S. Highway 385, Hot Springs, SD 57747 , U.S.A.

\begin{abstract}
Invasibility is a critical feature of ecological communities, especially for management decisions. To date, invasibility has been measured in numerous ways. Although most researchers have used the richness (or number) of exotic species as a direct or indirect measure of community invasibility, others bave used alternative measures such as the survival, density, or biomass of either a single or all exotic species. These different measures, even when obtained from the same communities, have produced inconsistent results and have made comparisons among communities difficult. Here, we propose a measure of the degree of invasion (DI) of a community as a surrogate for community invasibility. The measure is expressed as 2 independent components: exotic proportion of total species richness and exotic proportion of total species abundance (biomass or cover). By including richness and abundance, the measure reflects that the factors that control invasibility affect both of these components. Expressing exotic richness and abundance relative to the richness and abundance of all species in a community makes comparisons across communities of different sizes and resource availability possible and illustrates the importance of dominance of exotic species relative to natives, which is a primary management concern associated with exotic species.
\end{abstract}

Keywords: biomass, degree of invasion, exotic species, invasibility, species abundance, species diversity

Una Medida de Dos Partes del Grado de Invasión para Comparaciones entre Comunidades

Resumen: La invasibilidad es una característica crítica de las comunidades ecológicas, especialmente para las decisiones de manejo. A la fecha, la invisibilidad se ba medido de numerosas maneras. Aunque la mayoría de los investigadores ha utilizado la riqueza (o número) de especies exóticas como una medida directa o indirecta de la invasibilidad de la comunidad, otros han utilizados medidas alternativas como la supervivencia, densidad o biomasa de una o todas las especies exóticas. Estas medidas diferentes, aun cuando fueron obtenidas de las mismas comunidades, han producido resultados inconsistentes y ban dificultado las comparaciones entre comunidades. Aquí, proponemos una medida del grado de invasión (GI) de una comunidad como un sustituto de la invasibilidad de la comunidad. La medida se expresa en dos componentes independientes: la proporción de especies exóticas en relación con la riqueza total y la proporción exótica de la abundancia de especies total (biomasa o cobertura). Al incluir la riqueza y la abundancia, la medida refleja el hecho de que los factores que controlan la invasibilidad afectan a ambos componentes. La expresión de la riqueza y abundancia de especies exóticas en relación con la riqueza y abundancia de todas las especies en una comunidad hace que sean posibles las comparaciones entre comunidades de diferente tamaño $y$ disponibilidad de recursos e ilustra la importancia de la dominancia de especies exóticas en relación con las nativas, lo cual es una preocupación primaria relacionada con el manejo de especies exóticas.

Palabras Clave: abundancia de especies, biomasa, diversidad de especies, especies exóticas, grado de invasión, invasibilidad 


\section{Introduction}

Community invasibility has been a central focus in studies of biological invasions and ecosystem management, particularly in investigations of the complex interactions between exotics and natives. Nevertheless, owing to the lack of a standard definition, invasibility has been measured in many ways (Lonsdale 1999; Cleland et al. 2004), and to date results of studies show great variation in the relationships between invasibility and various biotic and abiotic variables across scales, habitats, and geographic regions. Most researchers studying habitat invasibility have used the richness of exotic species present as the measure of community invasibility (e.g., Lonsdale 1999; Byers \& Noonburg 2003; Herben et al. 2004; Davies et al. 2005), although some have used measures such as survivorship, establishment, density, size, and biomass (or cover) of individual or all exotic species in the community (e.g., Robinson et al. 1995; Kennedy et al. 2002; Smith et al. 2004; Von Holle \& Simberloff 2005). Although these studies shed light on biodiversity patterns and species assembly rules, the variety of definitions and inconsistent measures that exist make comparisons among communities and studies difficult.

There are 2 major unresolved issues in measuring invasibility. First, unless there is reasonable control of confounding factors, much of what is measured directly in the field reflects only the current degree of invasion (DI), not invasibility. Whereas invasibility is an intrinsic property of a community determined by factors (e.g., competition, herbivory, pathogens, climate) that affect the survival rates of newly arrived species in that community (Lonsdale 1999), DI measures the level at which a community has to date been invaded. The latter thus depends not only on community invasibility (Lonsdale 1999) but also on propagule pressure (e.g., the proximity to exotic species pools) and history or time (Fridley et al. 2004). Determining the relationship between DI and invasibility will further understanding of the mechanisms behind invasion and help managers set priorities for management of exotic species.

The second unresolved issue is that different measures (e.g., richness vs. biomass) from the same community at a given time can yield different DIs and lead to different conclusions, making comparisons among communities difficult. For example, in a fragmented oak savanna ecosystem, the species richness of exotics does not differ across a gradient of growing conditions, but the abundance of exotics increases significantly with decreasing stress (e.g., higher soil moisture; MacDougall et al. 2006). In riparian vegetation in France, covers of native and exotic species are negatively correlated, but their richness values are positively correlated (Tabacchi \& PlantyTabacchi 2005). Thus, implications for the invasibility of different communities (varying in productivity or native species richness, for example), and therefore potentially the degree of management attention received by these communities, depend on how DI is measured.

To accurately assess invasibility, compare invasibility among communities, and reveal the mechanisms underlying differences in invasibility, these 2 issues must be resolved, and resolving how DI is measured is an important step toward resolving the relationship between invasibility and DI. We argue that the richness of exotic species alone does not appropriately indicate DI or invasibility (Levine \& D'Antonio 1999) and that the abundance of exotic individuals alone is also inadequate. Instead, DI and community invasibility should be assessed as both proportional richness of exotics and their biomass dominance. Thus, we propose a 2-part measure of DI that, if applied consistently across many situations, could contribute to a clearer understanding of differences in invasibility among ecosystems. We focused on plant communities in natural and seminatural systems, but the same principles should apply to other communities as well.

\section{Degree of Invasion versus Invasibility}

Biotic invasion occurs when any new species establishes and persists, whereas a successful invader is a new species that significantly affects community structure and dynamics. We define invasibility as the degree to which an existing community is susceptible to new species' becoming established and persisting in it. There is no evidence that any community is saturated with species, especially at larger scales (Loreau 2000), or that the richness of exotic species in any community is at equilibrium (Davis et al. 2000; Herben et al. 2004). Thus, all communities are invasible to some degree (Williamson 1996) and a reasonable comparison of their invasibility may be made only when communities are under similar propagule pressure. On the other hand, DI is the extent to which new species already have become established and have persisted in a community. It is therefore a consequence of both intrinsic and extrinsic factors. The DI not only indicates a community's invasibility prior to the introduction of novel species, which is determined by intrinsic factors such as species diversity and the competitive abilities of the resident species, but it also reflects extrinsic factors such as propagule pressure on a community, introduced species' modes of introduction to the community, the fit of the introduced species to the community's environment, and the community's disturbance history and regime (Crawley et al. 1999; Lonsdale 1999; Davis et al. 2000).

There are many methods for investigating the invasibility of communities, including seed addition experiments and examining the performance of biocontrol agents and their hosting community. Nevertheless, owing to the ethically unpalatable possibility of introducing potentially harmful species into ecosystems when conducting field experiments, DI is the best indicator of invasibility 
available for most systems. Indeed, it is the only indicator available for observational studies investigating patterns across varying environmental conditions and it has been used extensively (e.g., Lonsdale 1999; MacDougall et al. 2006).

\section{Inadequacy of Number or Abundance of Exotic Species Alone} as Measures of DI and Invasibility

Many researchers who compared invasibility among communities used only the richness of exotic species in a community as their measure of DI. Nevertheless, we argue that exotic richness alone does not adequately measure DI and invasibility. This is because most exotics are not invasive (Williamson 1996) and all exotic species are not equivalent. Indeed, in some cases, the presence of many exotic species poses no major threat to native species, ecosystem functioning, or economic value of a community, especially when the exotics are low in abundance. For example, in the California chaparral, many exotic plant species only emerge with periodic fires, after which they are short-lived (e.g., Guo 2001). It is those few exotic species that attain great dominance in large areas-consequently eliminating or greatly reducing the abundance of many native species, affecting ecosystem functioning, or causing economic loss - that are invasive (by definition, sensu Davis et al. 2000) and are therefore targets of management actions. Thus, when measuring the DI of a community, what is most often ecologically and economically important is the biomass or dominance of invasives rather than the richness of exotic species.

On the other hand, exotic abundance (biomass or cover) alone is also an inadequate measure of DI. It does not indicate the potential for currently noninvasive exotics to become invasive through evolutionary or future habitat changes (Blossey \& Notzold 1995) or Allee effects (Taylor \& Hastings 2005). It also does not indicate the potential for positive interactions between exotic species. These positive interactions could lead to acceleration in the rate of accumulation and impact of new exotics (Simberloff \& Von Holle 1999; Grosholz 2005). For management purposes, abundance alone is inadequate because a high abundance of exotic species may represent a community with one dominant invasive that with proper treatment and reduction of propagule pressure, could be controlled or eradicated so that remaining natives can recover. In contrast, high abundance of exotic species could indicate a highly degraded community with little remnant native diversity and therefore little conservation value or restoration potential.

If, however, exotic richness and exotic abundance are highly correlated, the 2 measures of DI may be exchangeable. Similar to the sampling-effect hypothesis in biodiversity-ecosystem functioning theory (e.g., Huston 1997), one might argue that if the richness of exotic species in a community was high, the chances of it con- taining strongly competitive and therefore abundant exotic species would be high. This might be true, but the highly idiosyncratic nature of individual species' effects on biomass or cover (Symstad et al. 1998; Crawley et al. 1999) suggests that the relationship between exotic richness and abundance would be highly variable, especially at the lower end of the exotic-richness spectrum.

\section{Methods}

\section{A Two-Part Measure of Invasibility}

To overcome the problems outlined earlier, we propose a 2-part measure of DI, as an indicator of invasibility, in which the 2 terms consist of the proportions of total community species richness and biomass that are exotic:

$$
\mathrm{DI}=\left[\frac{S_{E}}{S_{T}}, \frac{M_{E}}{M_{T}}\right],
$$

where $S_{E}$ and $M_{E}$ are the richness and biomass of exotics in the community, respectively, and $S_{T}$ and $M_{T}$ are the richness and biomass of all species in the community, respectively. We used the proportion, instead of absolute amounts, of species richness and biomass to reduce the effects of factors such as area and resource availability, which also determine native richness and abundance. Unfortunately, biomass data are usually more difficult to obtain than richness data and this may be part of the reason for their limited usage. Nevertheless, reasonable surrogates of biomass, such as cover in plant communities, could be easily substituted in our proposed measure.

\section{Field Data}

To illustrate the problems of using exotic richness or exotic abundance alone as a measure of DI, we used survey data from 4 studies for which we have plot-level $\left(\leq 1 \mathrm{~m}^{2}\right)$ data to investigate the strength of various relationships among native and exotic biomass (or cover) and native and exotic richness. Then, to illustrate the usefulness of our proposed measure for comparisons across communities, we used community-level data (i.e., averaged over multiple plots) from these and other studies (Supplementary Material) to surmise the implications of a community falling within different regions of the state space defined by the 2-part measure.

\section{Results}

At the plot scale the trend for the relationship between exotic and native species tended to be negative, whether the measure was richness or cover/biomass (Fig. 1, left and right panels, respectively). Nevertheless, in half the cases (Figs. 1a-d), the relationship between native and exotic species was more clearly negative for 

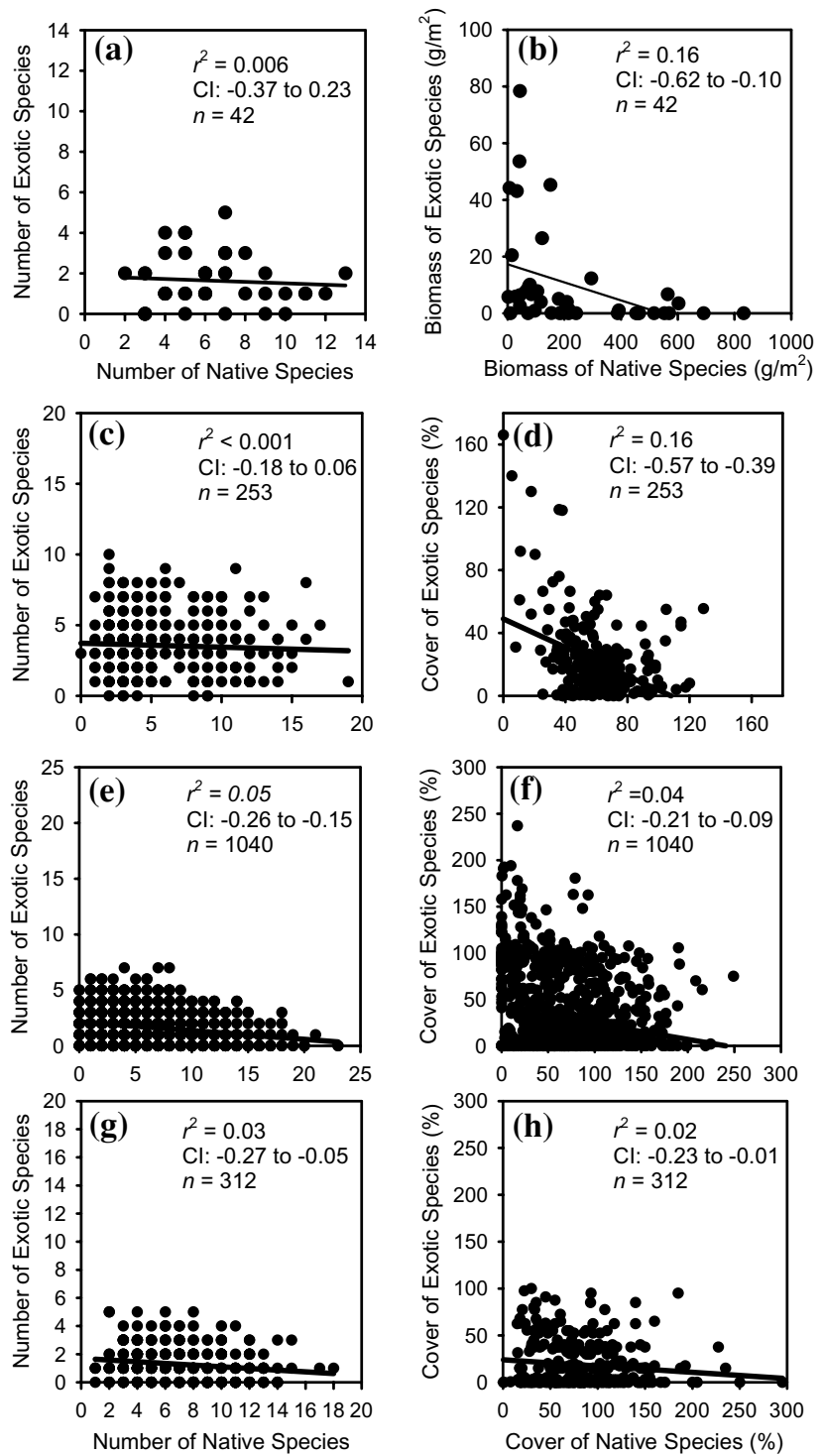

Figure 1. Examples of discrepancies in assessing invasibility or degree of invasion (DI) when different variables (number vs. abundance of native species) are used for the same community: $(a, b)$ Stunt Ranch, California, $(c, d)$ Lost Mound Refuge, Illinois, $(e, f)$ Northern Great Plains Parks, $(g, b)$ Jewel Cave National Monument, South Dakota. Species abundance (right-hand panels) is expressed as biomass in Stunt Ranch data and as accumulated percent cover for the other 3 locations. Confidence interval (CI) is 95\% for Pearson correlation coefficient. See Supplementary Material for sources of data.

biomass/cover than richness, as seen by the $95 \%$ CIs for correlation coefficients. Thus, if each of these cases were investigated separately, in 2 cases (Figs. 1e-h) a researcher could reach similar conclusions on the negative relationship between natives and exotics regardless of whether richness or abundance were measured; in one case (Figs. 1a-b) a researcher would find a weak negative relationship between natives and exotics with cover but very little evidence of a relationship with richness; and in the remaining case (Figs. 1c-d), a researcher would find a strong negative relationship between natives and exotics with cover but very little evidence for a relationship on the basis of richness.

Although we did find positive relationships between richness of exotic species and cover/biomass of exotic species in the 4 sites for which we had plot-level data, the strength of the correlations was not great, accounting for a maximum of $35 \%$ of the variance (Fig. 2, left panels). We found similar relationships between proportional richness and proportional cover/biomass of exotics (Fig. 2, right panels), but again, a considerable amount of the variation was not explained by these relationships.

We also found a positive correlation between proportional exotic richness and biomass/cover at the larger scale (Fig. 3), but the nature of the relationship was slightly different from that at the plot scale. Most notably, almost no points fell in the lower-right corner of the 2-part measure's state space, which yielded a steeper trend line in the large-scale relationship $(1.439 \pm 0.025)$ than in the small-scale relationships (slope [SE] of coefficient $=0.475$ [0.229], 0.997 [0.054], 1.015 [0.025], and $1.035[0.068])$.

\section{Discussion}

The variability of the strength of relationships between native and exotic species, depending on whether richness or cover/biomass are measured (Fig. 1), and the large scatter in relationships between richness and cover/biomass of exotic species (Fig. 2) illustrate that richness and cover/biomass of exotics are not interchangeable, but each contribute valuable information regarding the DI. The stronger correlations between proportional values compared with absolute values of richness and abundance were expected owing to the standardization effect; differences among microsites in resident species richness and habitat carrying capacity were eliminated. Thus, the proportional nature of our proposed DI measure allows for comparisons and inspections across widely varying habitats, but the information necessary to compile the index (absolute values of cover/biomass and species richness) may be critical in understanding the patterns seen in these comparisons.

The lack of communities with low exotic proportion of richness but high exotic proportion of cover/biomass (Fig. 3) may indicate that when exotics comprise a large proportion of diversity on these larger scales, native species have been reduced to a relatively minor component of the community. Conversely, communities with high exotic proportion of cover/biomass but low exotic proportion of richness indicate that a few exotics 

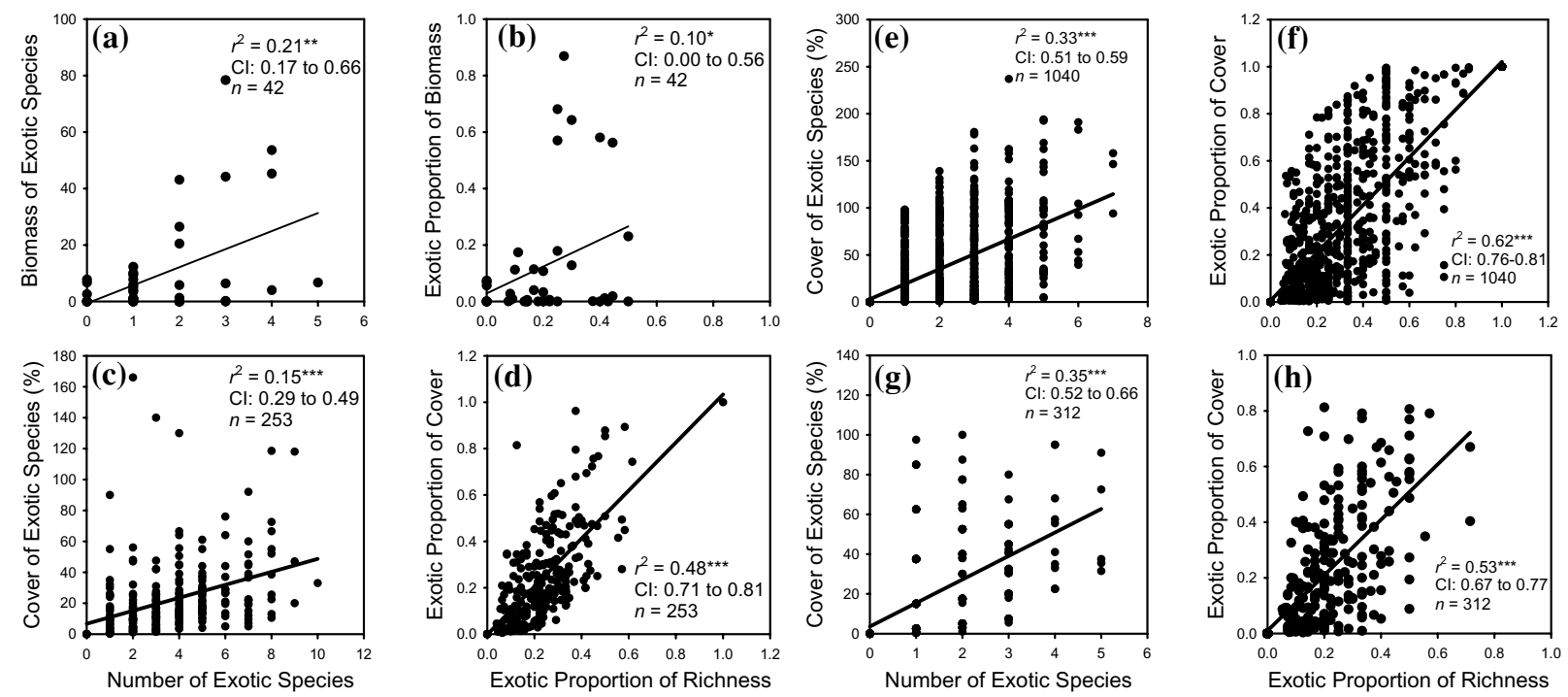

Figure 2. The relationships between absolute richness and cover/biomass (left) and between the exotic proportions of richness and cover/biomass at the plot scale from 4 studies (see Supplementary Material): $(a, b)$ Stunt Ranch, California, (c, d) Lost Mound Refuge, Illinois, (e, $f)$ Northern Great Plains parks, $(g$, b) Jewel Cave National Monument, South Dakota. Species abundance is expressed as biomass (grams per square meter) in Stunt Ranch data and as accumulated percent cover for the other 3 locations. Confidence intervals (CI) are 95\% for Pearson correlation coefficient $\left({ }^{*} \mathrm{p}<0.05,{ }^{* *} \mathrm{p}<0.01,{ }^{* * *} \mathrm{p}<0.0001\right.$ for null bypothesis of $\left.\mathrm{r}=0\right)$.

(invasives or super competitors) can account for a great amount of biomass in a community even when they are only a minor fraction of the richness. This difference between plot- and site-scale results could also be due to lower beta diversity of exotic species than native species and thus lower proportional richness of exotics over larger spatial scales.

\section{A Measure That Reflects Impacts and Determinants of Invasion}

Our 2-part measure of DI has 2 advantages over a singleelement measure. First, it reflects the impact of exotic species on a community in terms of diversity and resource use, highlighting the fact that they do not always correspond. As our data from a variety of sites show, it is not unusual for plots within a site to have a low exotic proportion of richness but a high exotic proportion of abundance. On the other hand, plots within a site with a high exotic proportion of richness and low exotic proportion of abundance were rare. The former could represent highly invasive individual species (e.g., kudzu [Pueraria lobata], purple loosestrife [Lythrum salicaria], cheatgrass [Bromus tectorum]), whereas the latter could suggest that there may be a threshold in the exotic proportion of richness beyond which native species decrease in richness and abundance. For example, the data from the studies shown in Fig. 3 suggest that once the exotic proportion of richness rises to $15 \%$ (inflection point of sigmoid curve), the chance that exotics comprise a large proportion of the biomass/cover increases dramatically. This may indicate some threshold for breakdown in the resistance of communities.

Second, the 2-part DI measure reflects 2 critical biotic elements that in turn affect DI or invasibility: resident diversity (e.g., Naeem et al. 2000; Kennedy et al. 2002) and biomass (Smith et al. 2004). Many researchers have examined invasibility in relation to native species diversity. In experimental studies in which extrinsic factors such as disturbance, climate, and soil fertility were controlled, the mechanism behind a negative diversity-invasibility relationship is greater niche occupation, which leaves fewer resources for an invading species (Naeem et al. 2000; Kennedy et al. 2002; Cleland et al. 2004). In some natural and seminatural communities, high native species richness does not necessarily mean high native biomass (e.g., Waide et al. 1999) and therefore full niche occupation. Instead, it may reflect disturbance or resource fluctuation, both of which also influence invasibility (Williamson 1996; Davis et al. 2000; Larson et al. 2001). For native species to be competitive with exotic colonists, they need time to build up sufficient biomass or cover to use space, nutrients, light, or other resources or to exert an influence on other species via other means (e.g., allelopathy) to their full capability. In a recently disturbed community, this is often not the situation. 


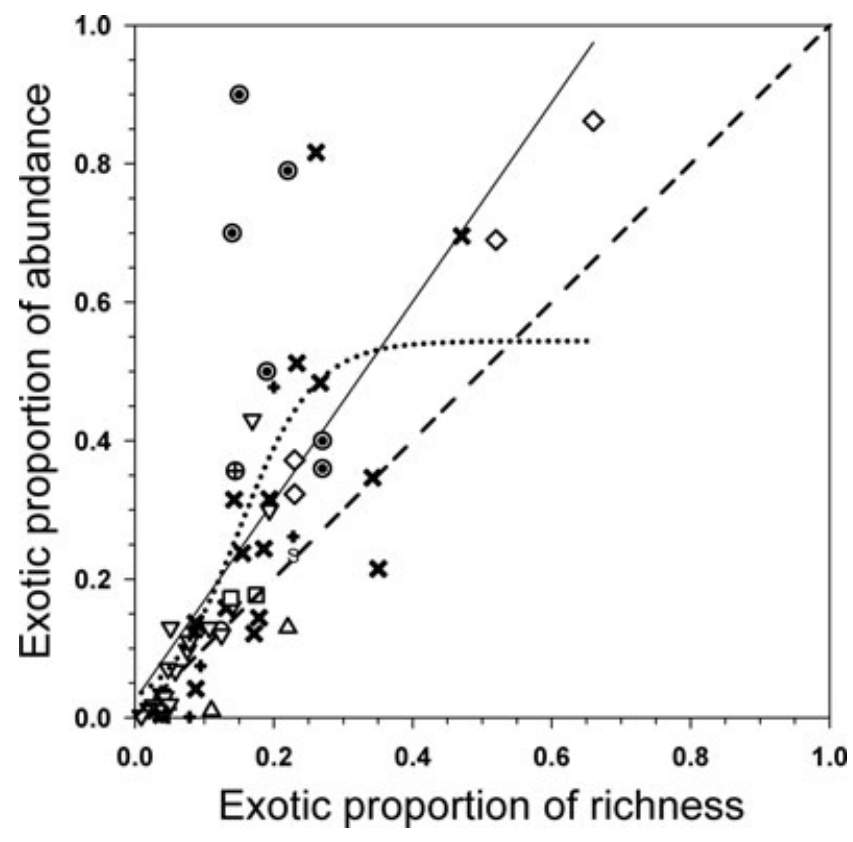

Figure 3. The relationship between the proportional exotic species richness and proportional exotic biomass or cover from 10 studies (61 habitat types) in the United States. Each symbol represents the mean value of all sampling plots from each habitat type, and different symbols (e.g., circle, square) correspond to different studies (see Supplementary Material). The solid straight line is from linear regression $\left(\mathrm{r}^{2}=0.51\right.$, $\mathrm{p}<0.0001)$; the dotted line is a sigmoid curve $(\mathrm{y}=$ $0.54 /\left(1+\exp \left(-\left(\mathrm{x}-\mathrm{x}_{0}\right) / 0.05\right) ; \mathrm{r}^{2}=0.51, \mathrm{p}<\right.$ $0.0001)$; and the dashed line is $\mathrm{y}=\mathrm{x}$.

\section{Other Measures of DI}

Density may also serve as a measure of DI and an indicator of invasibility, but we believe it is not as useful as biomass because the latter better reflects resource use (Guo \& Rundel 1997). For example, one large individual of a perennial bunchgrass species may use far more resources than many individuals of a small annual species. In general, plasticity of plant forms make the relationship between biomass and density nonlinear-positive when density is low and negative when density is high-which makes density a poor surrogate for biomass.

Measures of an individual species' performancesuch as germination, survivorship, density, biomass, or cover-in communities it invades are useful for understanding the interaction between that species and the community and are valuable for determining control methods, among other things. Performance of individual species also ultimately contributes to the 2 values comprising our 2-part measure of DI. Nevertheless, these measures are not readily transferable to other species or other communities and therefore are less useful for cross-system comparisons looking for general patterns of community invasibility.

\section{Practical Implications and Conclusions}

Knowing how different factors interact to determine invasibility makes it possible for managers to prioritize management of invaded communities. Numerous ecological studies have been devoted to determining native-exotic richness relationships, but the focus in management has mostly been on a single dominant invasive species such as leafy spurge (Euphorbia esula) or kudzu in the United States. In other words, many ecologists are interested in how many exotics are in a community and why (e.g., Tilman 1997), but land managers are more concerned about the biomass dominance and impacts of invasives (e.g., Barrows 1993), which are often related. Thus, community invasibility studies should focus on both biomass dominance and the richness of exotic species. The first part (biomass dominance) is clearly critical because of its relationship to the impact of exotic species on native communities. Nevertheless, as emphasized by our incorporation of both richness and biomass into our 2-part measure, we do not believe that examining and understanding exotic biomass is enough. Communities with high exotic species richness contain a high number of species that may become invasive in the future, that is, species that could explode when the right conditions occur, for example, because of a new disturbance or climate change.

The strength of the 2-part measure comes from the ability to investigate differences in and draw implications from the relationship between its 2 components. For example, if 2 sites have similar edaphic conditions but the relationship between the components is different (e.g., high richness, low biomass proportion in site $\mathrm{A}$ and low richness, high biomass proportion in site B), ecologists would be very interested in the causes, such as propagule pressure and length of time of interaction between natives and exotics (Mac Nally et al. 2004), and managers would discern the action needed in each condition (careful monitoring for outbreaks in A, biological control of dominant invasive in site B).

In sum, appropriate assessment of community DI and better understanding and predictability of community invasibility have important ecological and practical implications. As discussed earlier there are many other factors besides resident richness and biomass that determine invasibility of a community. Nevertheless, by incorporating these 2 factors that are known to influence it into a measure of DI, we are one step closer to determining the relationship between DI and invasibility. With a more consistent expression of DI across studies, patterns discerned from a wide set of conditions and communities should provide more predictive power of the invasibility of various communities. Although we used plants as 
examples, our proposed measure of DI should be readily extended to other communities.

\section{Acknowledgments}

We thank M. Burgman, B. Hanson, D. Larson, D. Lee, E. Main, N. Pavlovic, and anonymous reviewers for helpful comments and J. Butler and S. Wacker for use of their data. This study was supported by the U.S. Geological Survey.

\section{Supplementary Material}

Sources of material presented in Figs. 1-3 are available as part of the on-line article from http://www.blackwellsynergy.com/. The author is responsible for the content and functionality of these materials. Queries (other than absence of the material) should be directed to the corresponding author.

\section{Literature Cited}

Barrows, C. W. 1993. Tamarisk control II: a success story. Restoration and Management Notes 11:35-38.

Blossey, B., and R. Notzold. 1995. Evolution of increased competitive ability in invasive nonindigenous plants: a hypothesis. Journal of Ecology 83:887-889.

Byers, J. E., and E. G. Noonburg. 2003. Scale dependent effects of biotic resistance to biological invasion. Ecology 84:1428-1433.

Cleland, E. E., M. D. Smith, S. J. Andelman, C. Bowles, K. M. Carney, M. C. Horner-Devine, J. M. Drake, S. Emery, and D. B. Vandermast. 2004. Invasion in space and time: non-native species richness and relative abundance respond to interannual variation in productivity and diversity. Ecology Letters 7:947-957.

Crawley, M. J., S. L. Brown, M. S. Heard, and G. R. Edwards. 1999. Invasion-resistance in experimental grassland communities: species richness or species identity? Ecology Letters 2:140-148.

Davies, K. F., P. Chesson, S. Harrison, B. D. Inouye, B. A. Melbourne, and K. J. Rice. 2005. Spatial heterogeneity explains the scale dependence of the native-exotic diversity relationship. Ecology 86:1602-1610.

Davis, M. A., J. P. Grime, and K. Thompson. 2000. Fluctuating resources in plant communities: a general theory of invasibility. Journal of Ecology 88:528-534.

Fridley, J. D., R. L. Brown, and J. F. Bruno. 2004. Null models of exotic invasion and scale-dependent patterns of native and exotic species richness. Ecology 85:3215-3222.

Grosholz, E.-D. 2005. Recent biological invasion may hasten invasional meltdown by accelerating historical introductions. Proceedings of the National Academy of Sciences of the United States of America 102:1088-1091.

Guo, Q. 2001. Early post fire succession in California chaparral: changes in diversity, density, cover and biomass. Ecological Research 16:471-486.
Guo, Q., and P. W. Rundel. 1997. Measuring dominance-diversity in ecological communities: choosing the right variables. Journal of Vegetation Science 8:405-408.

Herben, T., B. Mandák, K. Bímová, and Z. Münzbergová. 2004. Invasibility and species richness of a community: a neutral model and a survey of published data. Ecology 85:3223-3233.

Huston, M. A. 1997. Hidden treatments in ecological experiments: re-evaluating the ecosystem function of biodiversity. Oecologia 110:449-460.

Kennedy, T. A., S. Naeem, K. M. Howe, J. M. H. Knops, D. Tilman, and P. Reich. 2002. Biodiversity as a barrier to ecological invasion. Nature 417:636-638.

Larson, D. L., P. J. Anderson, and W. Newton. 2001. Alien plant invasion in mixed-grass prairie: effects of vegetation type and anthropogenic disturbance. Ecological Applications 11:128-141.

Levine, J. M., and C. M. D'Antonio. 1999. Elton revisited: a review of evidence linking diversity and invasibility. Oikos 87:15-26.

Lonsdale, W. M. 1999. Global patterns of plant invasions and the concept of invasibility. Ecology 80:1522-1536.

Loreau, M. 2000. Are communities saturated? On the relationship between alpha, beta and gamma diversity. Ecology Letters 3:7376.

MacDougall, A. S., J. Boucer, R. Turkington, and G. E. Bradfield. 2006. Patterns of plant invasion along an environmental stress gradient. Journal of Vegetation Science 17:47-56.

Mac Nally, R., E. Fleishman, and D. D. Murphy. 2004. Influence of temporal scale of sampling on detection of relationships between invasive plants and the diversity patterns of plants and butterflies. Conservation Biology 18:1525-1532.

Naeem, S., J. M. H. Knops, D. Tilman, K. M. Howe, T. Kennedy, and S. Gale. 2000. Plant diversity increases resistance to invasion in the absence of covarying extrinsic factors. Oikos 91:97-108.

Robinson, G. R., J. F. Quinn, and M. L. Stanton. 1995. Invasibility of experimental habitat islands in a California winter annual grassland. Ecology 76:786-794.

Simberloff, D., and B. Von Holle. 1999. Positive interactions of nonindigenous species: invasional meltdown? Biological Invasons 1:2132.

Smith, M. D., J. Wilcox, T. Kelly, and A. K. Knapp. 2004. Dominance not diversity determines invasibility of tallgrass prairie. Oikos 106:253262.

Symstad, A. J., D. Tilman, J. Willson, and J. M. H. Knops. 1998. Species loss and ecosystem functioning: effects of species identity and community composition. Oikos 81:389-397.

Tabacchi, E., and A.-M. Planty-Tabacchi. 2005. Exotic and native plant community distributions within complex riparian landscapes: a positive correlation. Ecoscience 12:412-423.

Taylor, C. M., and A. Hastings. 2005. Allee effects in biological invasions. Ecology Letters 8:895-908.

Tilman, D. 1997. Community invasibility, recruitment limitation, and grassland biodiversity. Ecology 78:81-92.

Von Holle, B., and D. Simberloff. 2005. Ecological resistance to biological invasion overwhelmed by propagule pressure. Ecology 86:32123218.

Waide, R. B., M. R. Willig, C. F. Steiner, G. Mittelbach, L. Gough, S. I. Dodson, G. P. Juday, and R. Parmenter. 1999. The relationship between productivity and species richness. Annual Review of Ecology and Systematics 30:257-300.

Williamson, M. 1996. Biological invasions. Chapman \& Hall, London. 